\title{
Aqueous emulsion homo- and copolymerization of 1,3-dienes and styrene in the presence of $\mathrm{Cp}_{2} \mathrm{TiCl}_{2}$
}

\begin{abstract}
Stefania Pragliola, Teresa Acierno and Pasquale Longo
The aqueous emulsion homopolymerizations of 1,3-butadiene and isoprene were investigated using bis-cyclopentadienyl titanium dichloride $\left(\mathrm{Cp}_{2} \mathrm{TiCl}_{2}\right)$ as an active initiator. The copolymerizations of the same monomers with styrene were also performed. $\mathrm{Cp}_{2} \mathrm{TiCl}_{2}$, which has already been used for the production of atactic polystyrene, exhibited low activity in the homopolymerization of conjugated dienes, whereas better performance was obtained in copolymerization reactions. Both of the homopolymers, polybutadiene and polyisoprene, presented similar microstructures. The majority of the polymer chains were formed by 1,4-trans units and, to a lesser extent, by 1,4-cis and 1,2 (3,4 in the case of isoprene) units. All the copolymers presented a statistical distribution with atactic polystyrene sequences and 1,4-trans, 1,4-cis and 1,2 (3,4 in the case of isoprene) diene units. The copolymerization activity values and the percentage of inserted diene units were strictly correlated to the composition of the reaction mixture. The molecular weights of the co-polymers were substantially less than those detected for the styrene homopolymer and similar to those detected for polybutadiene and polyisoprene. Depending on the composition of the copolymer, the glass transition temperatures presented values between those of polystyrene and polydienes.
\end{abstract}

Polymer Journal (2013) 45, 904-908; doi:10.1038/pj.2013.7; published online 20 February 2013

Keywords: aqueous emulsion polymerization; conjugated dienes; transition metal catalysts

\section{INTRODUCTION}

Aqueous emulsion polymerization has become increasingly important since the middle of the past century because this technique can be applied to the production of a wide range of specialty polymers that are used in a variety of applications, such as coatings, paints, adhesives, binders, paper additives and so on. ${ }^{1-4}$ The use of water as a polymerization medium, which replaces the majority of the commonly used organic solvent-based systems, ensures considerable economic savings and important attention to the safeguard of the environment. ${ }^{1-4}$ In this framework, although free radical-initiated aqueous emulsion polymerization has been widely investigated, ${ }^{1-4}$ and is currently applied for the large-scale preparation of polymers, a deeper focus on metal-catalyzed aqueous emulsion polymerization has only recently been developed.

In this regard, late-transition metal-based species such as neutral nickel compounds or cationic palladium complexes have already been investigated in the aqueous emulsion polymerization of olefins because of their low oxophilicity. ${ }^{5-9}$ Stereospecific 1,3-butadiene polymerization leading to trans-1,4-polybutadiene in aqueous media catalyzed by rhodium salts was also reported as early as the 1960 s. ${ }^{10,11}$ Complexes of late-transition metals other than rhodium, such as cobalt complexes, are also well known to yield polybutadienes that present different microstructures. ${ }^{12-20}$ The best performance for this type of polymerization has been achieved using anionic emulsifiers such as alkylbenzene sulfonates. ${ }^{12-20}$ From the microstructural analysis of the obtained polymers and from comparative experiments with radical inhibitors, a coordination polymerization mechanism was also hypothesized.

Compared with late-transition metal-based species, early-transition metal-based species ${ }^{21-24}$ such as Ziegler-Natta or metallocene catalysts, which are well known to be extremely sensitive to moisture, have received less attention. The applications of these early-transition metal-based species were primarily focused in the field of coordination polymerization. ${ }^{25-27}$ Recently, the bis-cyclopentadienyl titanium dichloride $\left(\mathrm{Cp}_{2} \mathrm{TiCl}_{2}\right)$-mediated living radical polymerization of styrene and conjugated dienes in nonaqueous media has also been reported. ${ }^{28-31}$ Organo-titanium (III) species, which are readily obtained by the reduction of inexpensive $\mathrm{Cp}_{2} \mathrm{TiCl}_{2}$ with $\mathrm{Zn}$, have been reported to catalyze styrene, substituted styrene or conjugated diene living radical polymerization initiated by epoxides, peroxides or aldehydes. ${ }^{28-31}$

In the literature, a few articles by Bhattacharjee et al. ${ }^{32-36}$ have described the use of $\mathrm{Cp}_{2} \mathrm{MCl}_{2}$ (with $\mathrm{Cp}=$ cyclopentadienyl and $\mathrm{M}=\mathrm{Ti}, \mathrm{Zr}$ ) as an active catalytic precursor for the aqueous emulsion homopolymerization of styrene and methylmethacrylate. This $\mathrm{Cp}_{2} \mathrm{MCl}_{2}$-catalyzed reaction produced stereoirregular polymers that had high molecular weights. ${ }^{32-36}$ Moreover, in these reports, it has been hypothesized that the active catalytic species could be a cation such as $\left[\mathrm{Cp}_{2} \mathrm{MOH}\right]^{+}$, which is one of the species formed by the hydrolysis of $\mathrm{Cp}_{2} \mathrm{MCl}_{2},{ }^{37}$ stabilized by the large non-coordinating 
anion $n$-dodecylsulfate and utilized as an emulsifier. ${ }^{32-36}$ Although the polymerization mechanism has not been definitively determined, the authors suggested that the polymerization reaction start by insertion of a monomer into the 'labile' metal-hydroxyl group bond, which excludes the possibility of free radical or spontaneous polymerization. ${ }^{32-36}$

Herein, we present the first report on the aqueous emulsion homopolymerization of 1,3-butadiene and isoprene catalyzed by $\mathrm{Cp}_{2} \mathrm{TiCl}_{2}$ with sodium dodecylsulfate as a co-catalyst and the copolymerization of both diene monomers with styrene. The homoand copolymers were characterized using nuclear magnetic resonance spectroscopy (NMR) and thermal analysis, and their molecular weights and polydispersity index values were also determined using gel permeation chromatography.

\section{EXPERIMENTAL PROCEDURE}

\section{General procedure}

Styrene, isoprene, 1,3-butadiene, toluene, sodium $n$-dodecylsulfate (SDS) and $\mathrm{Cp}_{2} \mathrm{TiCl}_{2}$ were purchased from Sigma-Aldrich (Milan, Italy). Styrene and isoprene were purified by distillation over calcium hydride $\left(\mathrm{CaH}_{2}\right)$. Toluene was refluxed over sodium for $48 \mathrm{~h}$ and distilled before use. 1,3-butadiene, SDS and $\mathrm{Cp}_{2} \mathrm{TiCl}_{2}$ were used without further purification.

All polymerizations were conducted under a nitrogen atmosphere in degassed water at $50{ }^{\circ} \mathrm{C}$ following a procedure that was very similar to that previously described by Bhattacharjee and Patra. ${ }^{32}$

\section{Homopolymerization of isoprene and styrene}

A total of $0.05 \mathrm{~mol}$ of the monomer was emulsified in $80 \mathrm{ml}$ of an aqueous solution of SDS $\left(1.6 \times 10^{-3} \mathrm{~mol}\right)$, and then $20 \mathrm{ml}$ of a previously aged $(1 \mathrm{~h}$ at room temperature) aqueous solution of $\mathrm{Cp}_{2} \mathrm{TiCl}_{2}\left(5.0 \times 10^{-5} \mathrm{~mol}\right)$ was added. After $2 \mathrm{~h}$, the mixture was quenched in acidified methanol. The polymer was recovered by filtration, washed with fresh methanol and dried at $40{ }^{\circ} \mathrm{C}$ in a vacuum oven.

\section{Homopolymerization of 1,3-butadiene}

A total of $0.05 \mathrm{~mol}$ of the monomer was dissolved in $5 \mathrm{ml}$ of toluene and quickly transferred into $80 \mathrm{ml}$ of an aqueous solution of SDS $\left(1.6 \times 10^{-3} \mathrm{~mol}\right)$. The emulsion was thermostated at $50^{\circ} \mathrm{C}$, and then $20 \mathrm{ml}$ of a previously aged ( $1 \mathrm{~h}$ at room temperature) aqueous solution of $\mathrm{Cp}_{2} \mathrm{TiCl}_{2}\left(5.0 \times 10^{-5} \mathrm{~mol}\right)$ was added. After $2 \mathrm{~h}$, the mixture was quenched in acidified methanol. The polymer was recovered by filtration, washed with fresh methanol and dried at $40{ }^{\circ} \mathrm{C}$ in a vacuum oven.

\section{Copolymerization of diene with styrene}

The styrene-1,3-butadiene (S/B) and styrene-isoprene (S/I) copolymers were prepared following the same procedure used for the homopolymerization reactions using $0.05 \mathrm{~mol}$ of styrene and the appropriate amount of diene, as indicated in Tables 3 and 4.

\section{Polymer analysis}

NMR spectra were recorded on an AM 250 Bruker spectrometer (Bruker, Milan, Italy) operating at $62.89 \mathrm{MHz}$ at $298 \mathrm{~K}$. The samples were prepared by dissolving $40 \mathrm{mg}$ of polymer in $0.5 \mathrm{ml}$ of deuterated chloroform $\left(\mathrm{CDCl}_{3}\right)$. Tetramethylsilane was used as an internal reference for the chemical shifts. Calorimetric measurements were conducted on a DSC 2920 instrument manufactured by TA Instruments (Milan, Italy) under a flow of nitrogen $\left(\mathrm{N}_{2}\right)$ at a heating rate of $10^{\circ} \mathrm{C}$ per min.

The molecular weights and molar mass distributions of the polymers were measured by gel permeation chromatography at $30^{\circ} \mathrm{C}$, in which tetrahydrofurane (THF) was used as a solvent, the eluent flow rate was $1 \mathrm{ml} \mathrm{min}^{-1}$ and narrow polystyrene standards were used as references. The gel permeation chromatography measurements were performed on a Waters 1525 binary system equipped with a Waters 2414 RI detector (Waters, Milan, Italy) using four Styragel columns (range 1000-1000 $000 \AA$ ).

\section{RESULTS}

\section{Homopolymerization of 1,3-butadiene and isoprene}

The polymerizations of both monomers were conducted under a nitrogen atmosphere in degassed water at $50{ }^{\circ} \mathrm{C}$. The polymerization of isoprene was performed using the procedure described by Bhattacharjee and Patra ${ }^{32}$ for the polymerization of styrene, whereas in the case of 1,3-butadiene, the monomer was previously dissolved in toluene. All the reaction procedures used in this study are detailed in the Experimental procedure section.

The experimental data related to the homopolymerization of 1,3butadiene and isoprene are presented in Table 1. For comparison, the data related to the polymerization of styrene are also reported.

Both diene monomers polymerize, although their activities are less than that detected for styrene. The molecular weights of the polydienes are also less than those of polystyrene, whereas the polydispersity index values are comparable to those collected for polystyrene.

The microstructures of the polymers were determined by ${ }^{13} \mathrm{C} N \mathrm{NR}$ analysis. The NMR spectra of the polybutadiene and polyisoprene samples are presented in Figures $1 \mathrm{a}$ and $\mathrm{b}$, respectively. The resonances relative to the carbons of all recognized structural units were assigned on the basis of the data reported in the literature. ${ }^{38,39}$

The obtained polydienes exhibit similar microstructures. The polybutadiene chains are formed from $66 \%, 21 \%$ and $13 \%$ of $1,4-$ trans 1,4-cis and 1,2 units, respectively. The polyisoprene chains are also composed of $63 \%, 20 \%$ and $17 \%$ of 1,4 -trans, 1,4 -cis and 3,4 units, respectively. For both polymers, the 1,2 units of polybutadiene and the 3,4 units of polyisoprene are present in the polymer chains as isolated units. In fact, the obtained microstructures of both polybutadiene and polyisoprene are very similar to those of polydienes produced by the widely utilized industrial free radical polymerization. ${ }^{40}$

\section{Table 1 1,3-butadiene, isoprene and styrene homopolymerization} data

\begin{tabular}{lcccccc}
\hline Monomer & Yield $(g)$ & $\%$ Conv. & $\left.\begin{array}{c}A^{\mathrm{a}}(g \text { per } \\
m o l\end{array}\right)$ & $\begin{array}{c}M_{w} \text { Dalton } \\
\times 10^{5}\end{array}$ & $M W D^{\mathrm{b}}$ & $T_{g}^{\mathrm{c}}\left({ }^{\circ} \mathrm{C}\right)$ \\
\hline 1,3-butadiene & 0.10 & 3.7 & 1000 & 18.0 & 2.7 & -89.0 \\
Isoprene & 0.21 & 6.2 & 2100 & 7.1 & 3.6 & -49.2 \\
Styrene & 1.57 & 30 & 15700 & 54.0 & 2.4 & 100 \\
\hline
\end{tabular}

Abbreviations: $\mathrm{M}_{w}$, molecular weight; MWD, molar mass distribution.

${ }^{\mathrm{a}} \mathrm{A}$ (activity): $\mathrm{g}$ of polymer per mol of bis-cyclopentadienyl titanium dichloride

$\left(\mathrm{Cp}_{2} \mathrm{TiCl}_{2}\right) \times$ polymerization time $(\mathrm{h})$.

$\left(\mathrm{Cp}_{2} \mathrm{TiCl}_{2}\right) \times$ polymeriz
bPolydispersity index.

'Glass transition temperature.

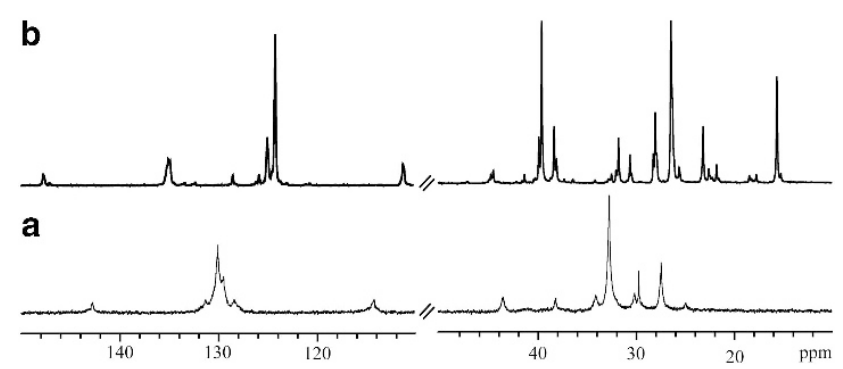

Figure 1 The ${ }^{13} \mathrm{C}$ nuclear magnetic resonance (NMR) spectra of polybutadiene (a) and polyisoprene (b) samples of Table 1. Tetramethylsilane scale, deuterated chloroform $\left(\mathrm{CDCl}_{3}\right)$, room temperature (RT). 
Finally, the glass transition temperatures of both the polybutadiene and polyisoprene samples are those expected for polymers that present similar microstructures. ${ }^{41,42}$

\section{Copolymerization of dienes (1,3-butadiene or isoprene) with styrene}

The copolymerizations were conducted under a nitrogen atmosphere in degassed water at $50{ }^{\circ} \mathrm{C}$. All the procedures used for the copolymerizations are described in the Experimental procedure section.

The obtained S/B and S/I copolymers were analyzed by ${ }^{13} \mathrm{C}$ NMR. The compositions of the copolymers are reported in Table 2.

As an example, the ${ }^{13} \mathrm{C}$ NMR spectra of samples $2 \mathrm{~B}$ and $3 \mathrm{I}$ in Table 2 are presented in Figures $2 \mathrm{a}$ and $\mathrm{b}$, respectively. The resonances relative to the carbons of all the recognized structural units were assigned on the basis of the data reported in the literature ${ }^{43-45}$ and are listed in the Supplementary Information.

All the copolymers present a statistical distribution with atactic polystyrene sequences and trans-1,4-, cis-1,4- and 1,2- (for S/B copolymers) and 3,4- (for S/I copolymers) diene units. Note that the percent content of different types of diene units in the copolymers are almost the same as that observed in diene homopolymers and

Table 2 S/B and S/I copolymer composition data

\begin{tabular}{|c|c|c|c|c|c|c|c|}
\hline \multirow[b]{3}{*}{ Sample } & \multirow[b]{2}{*}{$X_{S}$ in the } & \multirow[b]{3}{*}{ Comonomer } & \multirow{3}{*}{$\begin{array}{l}\text { \%comon. in the } \\
\text { copolymer }^{\mathrm{b}}\end{array}$} & \multicolumn{4}{|c|}{ Inserted diene units (\%) } \\
\hline & & & & & & & \\
\hline & $f e e d^{a}$ & & & 1,4-Trans & 1,4 -Cis & $1,2-$ & $3,4-$ \\
\hline $1 \mathrm{~B}$ & 0.60 & 1,3-butadiene & 22.9 & 62.3 & 17.9 & 19.8 & - \\
\hline 2B & 0.50 & 1,3-butadiene & 27.1 & 67.1 & 20.8 & 12.1 & - \\
\hline $3 B$ & 0.40 & 1,3-butadiene & 37.1 & 60.1 & 21.7 & 18.2 & - \\
\hline 4B & 0.30 & 1,3-butadiene & 41.2 & 65.6 & 17.3 & 17.1 & - \\
\hline $5 B$ & 0 & 1,3-butadiene & 100 & 66.0 & 20.9 & 13.1 & - \\
\hline 11 & 0.90 & Isoprene & 49.1 & 63.4 & 28.8 & - & 7.8 \\
\hline 21 & 0.50 & Isoprene & 57.3 & 61.3 & 32.6 & - & 6.1 \\
\hline 31 & 0.30 & Isoprene & 71.6 & 61.1 & 28.8 & - & 10.1 \\
\hline 41 & 0.20 & Isoprene & 76.5 & 64.4 & 31.8 & - & 3.8 \\
\hline 51 & 0 & Isoprene & 100 & 63.0 & 20.9 & - & 17.1 \\
\hline
\end{tabular}

Abbreviations: S/B, styrene-1,3-butadiene; S/I, styrene-isoprene.

${ }^{a}$ Molar fraction of styrene in the reaction mixture.

bMolar percentage of inserted diene units.

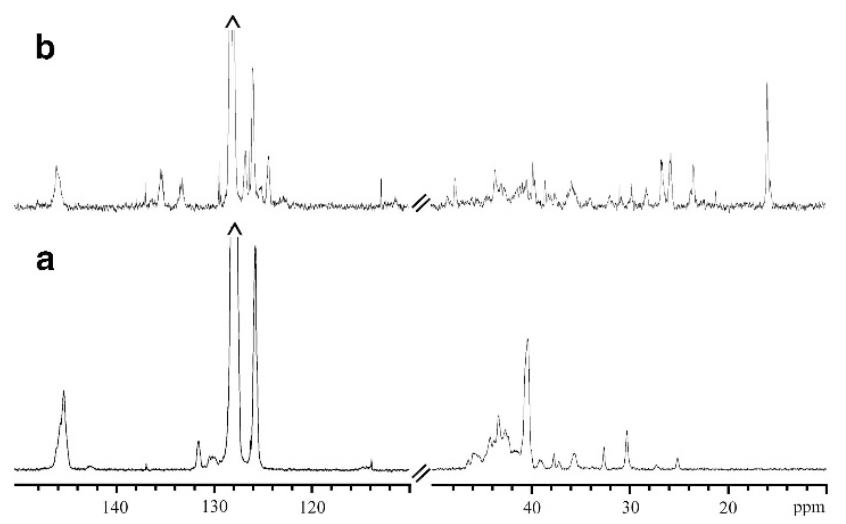

Figure 2 The ${ }^{13} \mathrm{C}$ nuclear magnetic resonance (NMR) spectra of samples 2B (a) and 3I (b) of Table 2. Tetramethylsilane scale, deuterated chloroform $\left(\mathrm{CDCl}_{3}\right)$, room temperature (RT). does not substantially depend on the content of styrene. As in the case of diene homopolymerization, these experimental data relative to the obtained copolymer microstructures support the hypothesis that diene homopolymerization and their copolymerization with styrene follow a free radical rather than an insertion mechanism. In fact, for the insertion polymerization mechanism, a strong dependence of the cis/trans diene units ratio from the content of copolymer styrene units is usually observed.

In Tables 3 and 4, the experimental data concerning the S/B and S/I copolymers are reported. As expected, the percentage of diene units in copolymer chains, which was evaluated via ${ }^{13} \mathrm{C}$ NMR measurements, is closely related to the amount of the diene monomer present in the reaction mixture. In fact, when the amount of diene in the feed is decreased, a decrease in the number of inserted diene units is observed.

The copolymerization activity values can also be correlated to the composition of the reaction mixture. Consistent with the lower homopolymerization activity observed for the dienes compared with styrene (see Table 1), a gradual decrease in the activity values with the increase of copolymer diene unit percentage was detected.

The molecular weights of both the S/B and S/I copolymers are significantly less than those observed for the styrene homopolymer and are comparable to those of polybutadiene and polyisoprene.

Table 3 S/B copolymer experimental data

\begin{tabular}{|c|c|c|c|c|c|c|}
\hline Sample & $\begin{array}{c}X_{S} \text { in the } \\
\text { feed }^{a}\end{array}$ & $\begin{array}{l}\%_{B} \text { in the } \\
\text { copolymer }\end{array}$ & $\begin{array}{c}A^{c} \\
(g \text { per mol } h)\end{array}$ & $\begin{array}{c}M_{w} \\
\text { Dalton } \times 10^{5}\end{array}$ & $M W D^{d}$ & $\begin{array}{l}T_{g}^{\mathrm{e}} \\
\left({ }^{\circ} \mathrm{C}\right)\end{array}$ \\
\hline$S^{f}$ & 1 & - & 15700 & 54.0 & 2.4 & 100 \\
\hline 1B & 0.60 & 22.9 & 5595 & 21.2 & 2.1 & 81.0 \\
\hline $2 B$ & 0.50 & 27.1 & 5851 & 19.3 & 2.2 & 61.6 \\
\hline $3 B$ & 0.40 & 37.3 & 2797 & 18.4 & 3.2 & 56.5 \\
\hline $4 B$ & 0.30 & 41.2 & 2711 & 17.9 & 2.6 & 51.8 \\
\hline $5 B$ & 0 & 100 & 1000 & 18.0 & 2.7 & -87.0 \\
\hline \multicolumn{7}{|c|}{$\begin{array}{l}\text { Abbreviations: } \mathrm{M}_{\mathrm{w}} \text {, molecular weight; MWD, molar mass distribution; S/B, styrene-1,3- } \\
\text { butadiene. } \\
\text { a Molar fraction of styrene in the reaction mixture. } \\
\text { b Molar percentage of inserted B units. } \\
\text { cA (activity): g of polymer per mol of bis-cyclopentadienyl titanium dichloride } \\
\left(\mathrm{Cp}_{2} \mathrm{TiCl}_{2}\right) \times \text { copolymerization time (h). } \\
\text { dPolydispersity index. } \\
\text { e } \mathrm{Glass} \text { transition temperature. }\end{array}$} \\
\hline
\end{tabular}

Table 4 S/l copolymer experimental data

\begin{tabular}{|c|c|c|c|c|c|c|}
\hline Sample & $\begin{array}{c}X_{S} \text { in the } \\
\text { feed }^{a}\end{array}$ & $\begin{array}{l}\% \text {, in the } \\
\text { copolymer }^{\mathrm{b}}\end{array}$ & $\begin{array}{c}A^{c}(g \text { per } \\
\text { mol } h)\end{array}$ & $\begin{array}{c}M_{w} \\
\text { Dalton } \times 10^{5}\end{array}$ & $M W D^{\mathrm{d}}$ & $T_{g}^{\mathrm{e}}\left({ }^{\circ} \mathrm{C}\right)$ \\
\hline$S^{f}$ & 1 & - & 15700 & 54.0 & 2.4 & 100 \\
\hline 11 & 0.90 & 49.1 & 4168 & 3.9 & 5.9 & 16.6 \\
\hline 21 & 0.50 & 57.3 & 3597 & 13.8 & 3.0 & -0.61 \\
\hline 31 & 0.30 & 76.5 & 3568 & 1.7 & 3.4 & -23.8 \\
\hline 41 & 0.20 & 71.6 & 3026 & 6.3 & 3.1 & -11.8 \\
\hline 51 & 0 & 100 & 2100 & 7.1 & 3.6 & -49.2 \\
\hline
\end{tabular}

Abbreviations: $\mathrm{M}_{\mathrm{w}}$, molecular weight; MWD, molar mass distribution; $\mathrm{S} / \mathrm{l}$, styrene-isoprene. a Molar fraction of styrene in the reaction mixture.

${ }^{b}$ Molar percentage of inserted isoprene units.

${ }^{\mathrm{C}} \mathrm{A}$ (activity): $\mathrm{g}$ of polymer per mol of bis-cyclopentadienyl titanium dichloride

$\left(\mathrm{Cp}_{2} \mathrm{TiCl}_{2}\right) \times$ copolymerization time $(\mathrm{h})$

dPolydispersity index.

'Glass transition temperature.

fPolystyrene sample. 


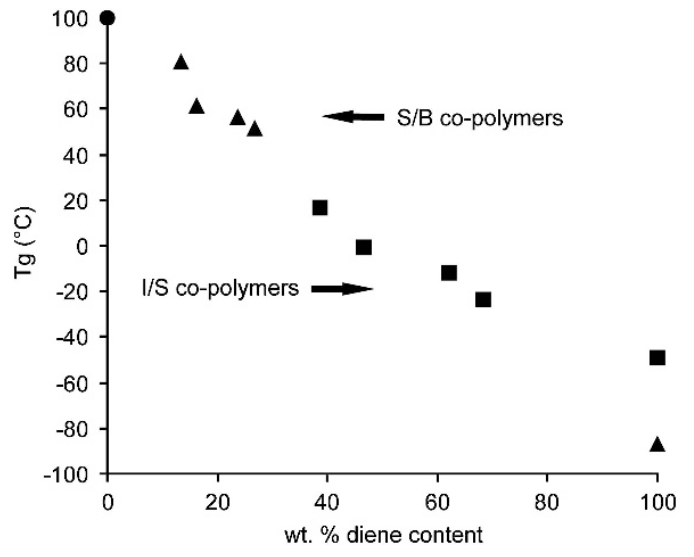

Figure 3 The styrene-1,3-butadiene ( $/ \mathrm{B} ; \mathbf{\Delta})$ and styrene-isoprene ( $\mathrm{S} / \mathrm{l}$; copolymer glass transition temperature values versus composition of the copolymer. Polystyrene $(\bullet)$

Moreover, a slight decrease in the molecular weights of the S/B copolymer, even if not really significant, was observed as the number of inserted 1,3-butadiene units increased, whereas in the case of the S/I copolymers, no correlation between their composition and molecular weight values was observed. The polydispersity index values of the S/B copolymer do not appear to be affected by the composition of the copolymer. The polydispersity index values of the S/I copolymer are greater than those of S/B copolymers, ranging between 2.5 and 6 . These data are consistent with the higher molecular weights detected for the S/I copolymers than those observed for the S/B copolymers.

Finally, a strong dependence of the glass transition temperatures of both the S/B and S/I copolymers on the copolymer composition was also observed. As expected for copolymers of monomers that yield amorphous homopolymers and provide a statistical distribution, the glass transition temperatures of the copolymers are between those observed for styrene and 1,3-butadiene homopolymers and decrease almost linearly with the increasing content of diene units (see Figure 3). In particular, the trend followed by the glass transition temperatures of the S/B copolymer very closely follows that predicted by the Fox equation. ${ }^{46}$

\section{CONCLUSIONS}

1,3-Butadiene and isoprene were investigated in aqueous emulsion homopolymerization using $\mathrm{Cp}_{2} \mathrm{TiCl}_{2}$ as an active catalytic precursor, which has already been used for the production of atactic polystyrene. Copolymerizations of the same monomers with styrene were also performed.

$\mathrm{Cp}_{2} \mathrm{TiCl}_{2}$ exhibited low activity in the homopolymerization of conjugated dienes, whereas better performance was obtained during copolymerization.

Both of the homopolymers, polybutadiene and polyisoprene, present similar microstructures. The majority of the polymer chains are formed by 1,4-trans units and, to a lesser extent, by 1,4-cis and 1,2 (3,4 in the case of isoprene) units.

All the copolymers present a statistical distribution with atactic polystyrene sequences and 1,4-trans, 1,4-cis and 1,2 (3,4 in the case of isoprene) diene units, and the percent content of different types of diene units in the copolymers is almost the same as that detected for homopolymers.

The copolymerization activity values and the percentage of inserted diene units are strictly correlated to the composition of the reaction mixture. When the diene monomer in the feed is decreased, a gradual decrease in the activity values and in the number of inserted diene units is observed.

The molecular weights of the copolymers are substantially less than those detected for the styrene homopolymer and similar to those detected for polybutadiene and polyisoprene.

A strong dependence of the copolymer glass transition temperatures on the compositions of the copolymers was also observed, and as expected for statistical copolymers, their values follow a linear trend and are between those observed for styrene and diene homopolymers.

From the experimental data related to the microstructures of the homo- and copolymers, the hypothesis that in both cases the reaction proceeds following a free radical mechanism, which is likely generated by $\mathrm{Ti}$ (III) species derived from the hydrolysis of $\mathrm{Cp}_{2} \mathrm{TiCl}_{2}$, should be considered, at least, to be an 'educated guess.' At the present, the nature of the titanium species responsible for the polymerization reaction has not yet been clarified, and therefore further experimental studies are in progress.

\section{CONFLICT OF INTEREST}

The authors declare no conflict of interest.

\section{ACKNOWLEDGEMENTS}

We thank Dr Patrizia Oliva, Dr Ivano Immediata and Dr Mariagrazia Napoli of the Department of Biology and Chemistry at the University of Salerno for their technical assistance. Financial support from the 'Ministero dell'Università e della Ricerca Scientifica e Tecnologica' (PRIN 2008) is gratefully acknowledged.

1 Lovell, P. A. \& El-Aasser, M. S. (eds) Emulsion Polymerization and Emulsion Polymers (Wiley, Chicester, England, 1997).

2 Urban, D. \& Takamura, K. (eds.) Polymer Dispersions and Their Industrial Applications (Wiley-VCH: Weinheim, Germany, 2002).

3 Asua, J. M. Emulsion polymerization: from fundamental mechanisms to process developments. J. Polym. Sci. A Polym. Chem. 42, 1025-1041 (2004).

4 Fitch, R. M. Polymer Colloids: A Comprehensive Introduction (Academic Press, San Diego, 1997).

5 Held, A., Bauers, F. M. \& Mecking, S. Coordination polymerization of ethylene in water by palladium(II) and nickel(II) catalysts. Chem. Commun. 301-302 (2000).

6 Held, A. \& Mecking, S. Coordination polymerization in water affording amorphous polyethylenes. Chem. Eur. J. 6, 4623-4629 (2000).

7 Bauers, F. M. \& Mecking, S. Aqueous homo- and copolymerization of ethylene by neutral nickel(II) complexes. Macromolecules 34, 1165-1171 (2001)

8 Soula, R., Novat, C. Tomov, A., Spitz, R., Claverie, J., Drujon, X., Malinge, J. \& Sudemont, T. Catalytic polymerization of ethylene in emulsion. Macromolecules 34, 2022-2026 (2001).

9 Johnson, L. K., Killian, C. M., Arthur, S. D., Feldman, J., McCord, E., McLain, S. J., Kreutzer, K. A., Bennet, M. A., Coughlin, E. B., Ittel, S., Parthasarathy, A., Tempel, D. J. \& Brookhart, M. S. $\alpha$-Diimine-transition metal complexes, their preparation and use as catalysts for (co)polymerization of (fluoro)olefins and olefinic esters (Du Pont) WO-A96/23010 (1996). Chem. Abstr. 125, 222773t (1996).

10 Rinehart, R. E., Smith, H. P., Witt, H. S. \& Romeyn, H. The preparation of trans 1,4polybutadiene by rhodium salts in solution. J. Am. Chem. Soc. 83, 4864-4865 (1961).

11 Canale, A. J., Hewett, W. A., Shryne, T. M. \& Youngman, E. A. Stereospecific polymerization of butadiene by transition metal salts in polar media. Chem. Ind. 1054-1055 (1962).

12 Henderson, J. N., Donbar, K. W., Barbour, J. B. \& Bell, A. J. Microencapsulated aqueous polymerization catalyst (Goodyear) US 4429085 (1984). Chem. Abstr. 100, 157154j (1984).

13 Burroway, G. L., Magoun, G. F. \& Gujarathi, R. N. Preparation of syndiotactic 1,2polybutadiene latex in presence of microencapsulated catalysts (Goodyear) US 5278263 (1991). Chem. Abstr. 112, 236729b (1990).

14 Burroway, G. L. Syndiotactic 1,2-polybutadiene synthesis in an aqueous medium utilizing N,N-dibutylformamide as a modifier (Goodyear) US 5278263 (1994). Chem. Abstr. 120, 218842u (1994).

15 Hidetomo, A., Kazuya, J. \& Haruo, U. Syndiotactic 1,2 polybutadiene with cobaltcarbon disulfide catalyst system. Catalysts for stereospecific polymerization of butadiene to syndiotactic 1,2-polybutadiene. J. Polym. Sci. Polym. Chem. Ed. 21, 1951-1972 (1983). 
16 Hidetomo, A., Kazuya, J. \& Haruo, U. Syndiotactic 1,2-polybutadiene with cobaltcarbon disulfide catalyst system. Mechanism of syndiotactic polymerization of butadiene with cobalt compounds-organoaluminum-carbon disulfide. J. Poym. Sci. Polym. Chem. Ed. 21, 1989-1995 (1983).

17 Ono, H., Ito, N., Kasai, K., Sakurai, N. \& Okuya, E. Polymer particles. Eur. Pat. App/ European patent 170456 (1986)

18 Ono, H. \& Kato, T. Stereoregular emulsion polymerization of butadiene. J. Polym. Sci. A Polym. Chem. 38, 1083-1089 (2000).

19 Monteil, V., Bastero, A. \& Mecking, S. 1,2-polybutadiene latexes by catalytic polymerization in aqueous emulsion. Macromolecules 38, 5393-5399 (2005).

20 Monteil, V., Wehrmann, P. \& Mecking, S. A general route to very small polymer particles with controlled microstructures. J. Am. Chem. Soc. 127, 14568-14569 (2005).

21 Fink, G., Mülhaupt, R. \& Brintzinger, H. H. Ziegler Catalysts (Springer, Berlin, 1995).

22 Brintzinger, H. H., Fischer, D., Mülhaupt, R., Rieger, B. \& Waymouth, R. Stereospecific olefin polymerization with chiral metallocene catalysts. Angew. Chem. Int. Ed. Eng/. 34, 1143-1170 (1995).

23 Britovsek, G. J. P., Gibson, V. C. \& Wass, D. F. The search for new-generation olefin polymerization catalysts: life beyond metallocenes. Angew. Chem. Int. Ed. Engl. 38, 428-447 (1999).

24 Kaminsky, W. \& Arndt, M. Metallocenes for polymer catalysis. Adv. Polym. Sci. 127, 143-187 (1997).

25 Resconi, L., Cavallo, L., Fait, A. \& Piemontesi, F. Selectivity in propene polymerization with metallocene catalysts. Chem. Rev. 100, 1253-1346 (2000).

26 Razavi, A. \& Thewalt, U. Site selective ligand modification and tactic variation in polypropylene chains produced with metallocene catalysts Coord. Chem. Rev. 250, 155-169 (2006).

27 Delferro, M. \& Marks, T. J. Multinuclear olefin polymerization catalysts. Chem. Rev. $111,2450-2485$ (2011)

28 Asandei, A. D., Chen, Y., Saha, G. \& Moran, I. W. Cp2TiCl-catalyzed radical chemistry: living styrene polymerizations from epoxides, aldehydes, halides and peroxides. Tetrahedron 64, 11831-11838 (2008).

29 Asandei, A. D., Simpson, C. P., Yu, H. S., Adebolu, O. I., Saha, G. \& Chen, Y. Cp2TiClcatalyzed controlled radical polymerization of isoprene initiated by epoxide radical ring opening. ACS Symp. Ser. Control./Living Radic. Polym. 1024, 149-166 (2009).

30 Asandei, A. D. \& Chen, Y. Cp2TiCl-catalyzed SET Reduction of aldehydes: a new initiating protocol for living radical polymerization. Macromolecules 39, 7459-7554 (2006).

31 Asandei, A. D., Moran, I. W., Saha, G. \& Chen, Y. Ti-mediated living radical styrene polymerizations. 6. $\mathrm{Cp} 2 \mathrm{TiCl}$-catalyzed initiation by epoxide radical ring opening: effect of reducing agents, temperature, Ti/Epoxide and Ti/Zn ratios. J. Polym. Sci. A Polym. Chem. 44, 2156-2165 (2006).
32 Bhattacharjee, M. \& Patra, B. N. $\left[\mathrm{Cp}_{2} \mathrm{TiCl}_{2}\right]$ as polymerization catalyst in aqueous medium: polymerization of styrene in water. J. Organomet. Chem. 689, 1091-1094 (2004).

33 Bhattacharjee, M. \& Patra, B. N. $\left[\mathrm{Cp}_{2} \mathrm{TiCl}_{2}\right]$ Catalyzed polymerization in water: polymerization of methyl methacrylate to a high molecular weight polymer. Polymer 45, 3111-3114 (2004)

34 Patra, B. N. \& Bhattacharjee, M. Synthesis of high molecular weight polystyrene and poly(methyl methacrylate) with low polydispersity by [Cp2 $\mathrm{ZrCl} 2]$ catalyzed aqueous polymerization. J. Polym. Sci. A Polym. Chem. 43, 3797-3803 (2005).

$35 \mathrm{De}, \mathrm{S}$. K. \& Bhattacharjee, M. An environmentally benign room temperature aqueous homo- and copolymerization of styrene and methyl methacrylate catalyzed by [Cp2TiCl2]/NaBPh4. J. Polym. Sci. A Polym. Chem. 47, 6496-6503 (2009).

36 De, S. K. \& Bhattacharjee, M. Synthesis of high molecular weight polymer nanoparticles by [Cp2ZrCl2] catalyzed emulsion polymerization. J. Polym. Sci. A Polym. Chem. 49, 3920-3927 (2011).

37 Bottrill, M., Gavens, P. D., Kelland, J. W. \& McMeeking, J. in Comprehensive Organometallic ChemistryWilkinson, G. (eds. Vol. 3, 331-431 (Pergamon Press, Oxford, 1982).

38 Matsuzaki, K., Uryu, T. \& Asakura, T. NMR Spectroscopy and Stereoregularity of Polymers 41-50 (Japan Scientific Societies Press, 1996).

39 Tanaka, Y. \& Sato, H. Sequence distribution of polyisoprenes. Polymer 17, 413-418 (1976).

40 Obrecht, W. Ullmann's Encyclopedia of Industrial Chemistry. 6th ednVol. 31, 461-600 (Wiley-VCH, Weinheim, Germany,, 2003).

41 Widmaier, J. M. \& Meyer, G. C. Glass transition temperature of anionic polyisoprene Macromolecules 14, 450-452 (1981).

42 Sircar, A. K. Characterization of isomeric elastomers using thermal analysis. J. Ther. Anal. 49, 293-301 (1997).

43 Zambelli, A., Caprio, M., Grassi, A. \& Bowen, D. E. Syndiotactic styrene-butadiene block copolymers synthesized with $\mathrm{CpTiX} 3 / \mathrm{MAO}(\mathrm{Cp}=\mathrm{C} 5 \mathrm{H} 5, X=\mathrm{Cl}, \mathrm{F} ; \mathrm{Cp}=\mathrm{C} 5 \mathrm{Me} 5$, $\mathrm{X}=\mathrm{Me})$ and TiXn/MAO $(\mathrm{n}=3, \mathrm{X}=\mathrm{acac} ; \mathrm{n}=4, \mathrm{X}=0$-tert-Bu). Macromol. Chem. Phys. 201, 393-400 (2000).

44 Caprio, M. Serra, M. C., Bowen, E. D. \& Grassi, A. Structural characterization of novel styrene-butadiene block copolymers containing syndiotactic styrene homosequences. Macromolecules 35, 9315-9322 (2002).

45 Cuomo, C., Serra, M. C., Gonzalez-Maupoey, M. \& Grassi, A. Copolymerization of styrene with butadiene and isoprene catalyzed by the monocyclopentadienyl titanium

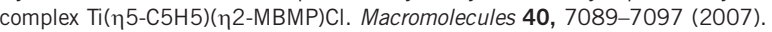

46 Fox, T. Influence of diluent and of copolymer composition on the glass temperature of a polymer system. Bull. Am. Phys. Soc. 123, 1 (1956).

Supplementary Information accompanies the paper on Polymer Journal website (http://www.nature.com/pj) 